ARTICLE

\title{
Decreasing delivery room CPAP-associated pneumothorax at $\geq 35$-week gestational age
}

Edward F. Stocks ${ }^{1,3}$, Mambarambath Jaleel ${ }^{1}$, William Smithhartt ${ }^{1,4}$, Patti J. Burchfield ${ }^{1}$, Anita Thomas ${ }^{1}$, Kate Louise M. Mangona ${ }^{1}$, Vishal Kapadia (D ${ }^{1}$, Myra Wyckoff ${ }^{1}$, Venkatakrishna Kakkilaya ${ }^{1}$, Shelby Brenan ${ }^{1,5}$, L. Steven Brown ${ }^{2}$, Christopher Clark $^{2}$, David B. Nelson ${ }^{1,2}$ and Luc P. Brion (iD ${ }^{1 凶}$

(c) The Author(s), under exclusive licence to Springer Nature America, Inc. 2022

OBJECTIVE: We previously reported an increase in pneumothorax after implementing delivery room (DR) continuous positive airway pressure (CPAP) for labored breathing or persistent cyanosis in $\geq 35$-week gestational age (GA) neonates unexposed to DR-positive pressure ventilation (DR-PPV). We hypothesized that pneumothorax would decrease after de-implementing DR-CPAP in those unexposed to DR-PPV or DR-O ${ }_{2}$ supplementation (DR-PPV/O $\mathrm{O}_{2}$ ).

STUDY DESIGN: In a retrospective cohort excluding DR-PPV the primary outcome was DR-CPAP-related pneumothorax (1st chest radiogram, 1st day of life). In a subgroup treated by the resuscitation team and admitted to the NICU, the primary outcome was DR-CPAP-associated pneumothorax (1st radiogram, no prior PPV) without DR-PPV/O 2 .

RESULTS: In the full cohort, occurrence of DR-CPAP-related pneumothorax decreased after the intervention $(11.0 \%$ vs $6.0 \%$, $P<0.001)$. In the subgroup, occurrence of DR-CPAP-associated pneumothorax decreased after the intervention $(1.4 \%$ vs. $0.06 \%$, $P<0.001)$.

CONCLUSION: The occurrence of CPAP-associated pneumothorax decreased after avoiding DR-CPAP in $\geq 35$-week GA neonates without DR-PPV/O 2 .

Journal of Perinatology (2022) 42:761-768; https://doi.org/10.1038/s41372-022-01334-4

\section{INTRODUCTION}

The International Liaison Committee on Resuscitation (ILCOR) remarked in 2010 that in contrast with preterm infants "there is no evidence to support or refute the use of delivery room (DR)continuous positive airway pressure (CPAP) in the term baby" [1-6]. Despite the paucity of evidence, the neonatal resuscitation program (NRP), the ILCOR and the Japanese Resuscitation Council, but not the European Resuscitation Council, added consideration of CPAP for any gestational age (GA) neonate with "labored breathing" or "persistent cyanosis," but otherwise normal heart rate and spontaneous respiration without gasping [7-9]. The change in guidelines was followed by increased use of DR-CPAP and a $40-47 \%$ increase in pneumothorax (from $0.8 \%$ to $1.2 \%$ in Japan and from $0.38 \%$ to $0.56 \%$ at Parkland Hospital) in term and late preterm infants $[10,11]$. Retrospective cohort studies suggested an association of DR-CPAP with pneumothorax in term and late preterm infants [10-17]. The frequency of pneumothorax among term or late preterm infants exposed to CPAP and admitted to the NICU ranges between $5 \%$ and $17 \%[11,13,15]$. In one study of neonates who were admitted to the newborn nursery after DR-CPAP, the frequency of pneumothorax was $2 \%$ among those who received DR-CPAP without DR-positive pressure ventilation (PPV) and $0 \%$ among those who received both DR-PPV and DR-CPAP [18].

In a cohort at Parkland Hospital including term and late preterm infants without DR-PPV, the frequency of symptomatic pneumothorax and thoracentesis/thoracostomy increased by $47 \%$ after implementing new NRP guidelines [11, 12]. The association of pneumothorax with DR-CPAP was stronger in neonates receiving room air than in those receiving supplemental oxygen in the DR $\left(\mathrm{DR}-\mathrm{O}_{2}\right)$ [11]. Concerns were raised about lack of information on neonates admitted to the newborn nursery, NICU admission rate, length of stay, and lack of a protocol for radiograms in that study [19].

Randomized controlled trials (RCTs) have demonstrated benefits of CPAP for respiratory distress in late-preterm infants and term neonates with $\mathrm{O}_{2}$ requirement. In contrast, to our knowledge there is no evidence from RCTs supporting DR-CPAP for neonates receiving neither DR-PPV nor $D R-\mathrm{O}_{2}\left(\mathrm{DR}-\mathrm{PPV} / \mathrm{O}_{2}\right)$. In neonates with transient tachypnea of the newborn, CPAP versus free-flow $\mathrm{O}_{2}$ reduced the duration and severity of respiratory distress but did not affect the need for mechanical ventilation [20, 21]. In neonates with meconium aspiration syndrome, CPAP reduced the need for mechanical ventilation [22]. In neonates born at $\geq 30$ weeks GA with respiratory distress in nontertiary centers, CPAP versus $\mathrm{O}_{2}$ alone reduced treatment failure or need for up-transfer [23]. In neonates born at $\geq 31$ weeks GA with respiratory distress in special care nursery, high-flow nasal cannula resulted in more frequent respiratory failure than CPAP [24]. In neonates born at $34^{0 / 7}-38^{6 / 7}$ weeks GA by elective cesarean section, prophylactic DR-CPAP at $5 \mathrm{~cm}$ with $24-30 \% \mathrm{O}_{2}$ for $20 \mathrm{~min}$ starting at $\leq 10 \mathrm{~min}$ of life

\footnotetext{
${ }^{1}$ University of Texas Southwestern Medical Center, Dallas, TX, USA. ${ }^{2}$ Parkland Health \& Hospital System, Dallas, TX, USA. ${ }^{3}$ Present address: Oklahoma University, Norman, OK, USA. ${ }^{4}$ Present address: Newborn Associates, Jackson, MO, USA. ${ }^{5}$ Present address: Pediatrix, Colorado Springs, CO, USA. ${ }^{\circledR}$ email: luc.brion@utsouthwestern.edu
} 
reduced total NICU admissions; however, it did not reduce transient tachypnea or NICU admissions for respiratory distress compared with controls of which $31 \%$ received $\mathrm{DR}-\mathrm{O}_{2}$. No neonate in that latter study developed a pneumothorax [25].

We hypothesized (1) that the occurrence of pneumothorax on the first day of life in term and late-preterm neonates not requiring DR-PPV $/ \mathrm{O}_{2}$ could be reduced by $50 \%$ after avoiding DRCPAP and (2) that pneumothorax was independently associated with DR-CPAP.

\section{METHODS \\ Setting}

Parkland Hospital is a large county hospital with $\sim 12,000$ total deliveries each year. Parkland's NICU serves around 1300 patients per year in a 96bed unit. All low-risk deliveries are attended by an NRP-trained nurse and pediatric resident or pediatric nurse practitioner. Criteria for direct admission from the DR to the Mother-Baby-Unit include the following: stable neonates of $G A \geq 35$ weeks and birth weight $\geq 2100 \mathrm{~g}$; Apgar score $\geq 7$ at five minutes; maximum 3 min of DR-PPV; lack of symptoms at the time of leaving the DR (maximum 30 min of age); lack of maternal diabetes mellitus class B or higher; and lack of congenital anomalies needing monitoring or surgery within $24 \mathrm{~h}$.

A NICU resuscitation team is called to the DR for neonates at high risk for needing resuscitation (e.g., malformations), fetal compromise (i.e., nonreassuring fetal heart tones) or poor respiratory effort not resolving with short-term PPV with a self-inflating bag. The resuscitation team is comprised of a resuscitation nurse, respiratory therapist, and neonatal nurse practitioner or pediatric resident. Assisting as needed are an inhouse NICU fellow and neonatology attending.

Skills and knowledge of the NRP guidelines are regularly assessed and reinforced using simulation and ongoing training. DR interventions are documented by the resident or nurse practitioner and by the resuscitation nurse in the electronic health record (EHR). During high-risk deliveries, an obstetric nurse records interventions on a paper chart in real time. This paper record is scanned into the EHR.

On July 1st 2011, Parkland Hospital implemented the 2010 NRP which allowed DR-CPAP for neonates with labored breathing or persistent cyanosis (Supplementary Fig. 1). CPAP was started at $5 \mathrm{~cm} \mathrm{H}_{2} \mathrm{O}$ and increased by $1 \mathrm{~cm}$ as needed (maximum $7 \mathrm{~cm}$ ). DR-CPAP was provided with facemask and Neopuff T-piece resuscitator with $10 \mathrm{~L} / \mathrm{min}$ flow rate. If the patient required CPAP for transport to the NICU, the patient was transitioned to bi-nasal prongs (Hudson Prongs; Teleflex, Wayne, PA) connected to a positive end expiratory pressure valve with $10 \mathrm{~L} / \mathrm{min}$ flow.

In 2012, Parkland standardized criteria for chest radiogram for late preterm and term neonates admitted to the NICU due to respiratory distress or concerns for sepsis in order to prevent irradiation of neonates without rapidly resolving mild symptoms (Supplementary Fig. 2).

\section{Design and inclusion and exclusion criteria}

This retrospective cohort study included (1) a full birth cohort consisting of all neonates born at $\geq 35$ weeks GA from $01 / 01 / 2012$ to 12/31/2020, excluding those who received DR-PPV and (2) a NICU subgroup consisting of neonates who had a resuscitation team call and were subsequently admitted to the NICU.

Infants born 01/01/2012 to 03/31/2017 constituted the pre-intervention epoch or Epoch-1. Infants born in 2012-2015 were included in a previous study [11]; in the current study data on pneumothorax were limited to the first radiogram on the first day of life and individual patient-level data were extracted in the full cohort. Infants born 04/01/2017 to 12/31/2020 constituted the post-intervention epoch or Epoch-2.

\section{Intervention (Supplementary Fig. 1)}

The intervention was the adoption of guidelines directing the resuscitation team to avoid DR-CPAP from neonates $\geq 35$-weeks GA exhibiting grunting, tachypnea, or retractions without preductal saturation lower than the range of NRP guidelines; these infants were observed without supplemental $\mathrm{O}_{2}$ and without CPAP in the DR. Neonates with lower saturation were provided with supplemental $\mathrm{O}_{2}$ and DR-CPAP was considered according to the most recent NRP guidelines (versions 6 and 7). All the other interventions were those of the NRP guidelines. The resuscitation team continued to observe neonates in the DR until they no longer had respiratory distress and were off CPAP and off $\mathrm{O}_{2}$. If respiratory distress,
CPAP or supplemental $\mathrm{O}_{2}$ persisted for $>30 \mathrm{~min}$, they were admitted to the NICU.

The team including faculty and fellows involved in this project initiated a series of presentations at divisional and resuscitation meetings directed at increasing buy-in from all stakeholders, including all members of the resuscitation team. The resuscitation neonatology attending ensured each cohort of residents adhered to the new protocol by directing training simulations.

\section{Outcome variables}

For the full cohort, data were collected by electronic capture from the EHR to create a database of all neonates born at 35-43 weeks GA. Electronic capture of pneumothorax used natural language processing (NLP) of free text in the radiologist's impression and narrative, i.e., text-processing technique combining computer programming with linguistics, allowing collection of unstructured data from notes (key words, abbreviations, acronyms) [26]. The algorithm was validated by comparing predicted pneumothorax by logistic regression analysis using the algorithm (Supplementary Table 1) with pneumothorax documented by chart review in neonates in several neonates the NICU subgroup. Cohen kappa was $\geq 0.9$ for all variables [27].

The primary outcome for the full cohort was DR-CPAP-related pneumothorax, i.e., after DR-CPAP, noted on the radiologist's impression of the first radiogram during the first 24 hours of life. Secondary measures were NICU admissions and length of stay in NICU.

For the NICU subgroup, data were collected prospectively from two prospective databases: the DR resuscitation database and the NICU database and by additional data extraction from the EHR. Data included DR-CPAP, DR- ${ }_{2}$, GA, sex, weight, length, race/ethnicity and pneumothorax diagnosed by the radiologist on the first radiogram during the first 24 hours of life. GA was obtained from the best obstetrical estimate except for women with late prenatal care if the neonatal GA estimate by modified Ballard score differed from the obstetrical estimate by $>2$ weeks.

The primary outcome for the NICU subgroup was DR-CPAP-associated pneumothorax, defined as pneumothorax noted on the first radiogram during the first $24 \mathrm{~h}$ of life after exposure to DR-CPAP excluding CPAP initiated in the NICU and any prior PPV. Each diagnosis of pneumothorax was verified by individual chart review as positive chest radiogram reading (impression) from a pediatric radiologist or confirmation by a single pediatric radiologist $(\mathrm{KM})$ in case the reading was equivocal. A secondary outcome was provision of thoracentesis or thoracostomy.

Secondary outcomes among neonates without DR-PPV/O $\mathrm{O}_{2}$ included occurrence of DR-CPAP usage for respiratory distress and occurrence of spontaneous pneumothorax. A spontaneous pneumothorax was defined as a pneumothorax diagnosed on the first chest radiogram on the first day of life in a neonate who had not received any positive pressure (CPAP or PPV) any time before diagnosis of the pneumothorax. Secondary outcomes among neonates with DR-O $\mathrm{O}_{2}$ but without DR-PPV included occurrence of CPAP usage, occurrence of CPAP-associated pneumothorax and occurrence of spontaneous pneumothorax.

\section{Analysis}

Continuous variables are presented as mean (SD) or median (interquartile range [IQR]). Statistical analyses were done using SPSS version 28 for Mac (IBM, Inc, Armonk, NY) or SAS 9.4 (SAS Institute, Inc, Cary, NC) for two-tailed tests, with $P<0.05$ considered significant. Analyses included chi-square analysis, Student's $t$ test, Mann-Whitney test, chi-square analysis, Fisher's exact test, Cohen kappa (exact test) and intraclass correlation coefficient. Changes over time were analyzed, depending on data distribution, by statistical process control (P chart, Montgomery rules) using QI Macros for Excel (KnoWare International, Denver, CO) (if baseline was stable), or by interrupted time series analysis to evaluate secular trends [28].

In the full cohort, the association of pneumothorax with DR-CPAP was assessed by generalized linear regression with Poisson distribution and robust estimate to calculate the adjusted relative risk (aRR), risk difference (aRD) and number needed to harm (aNNH), taking into account epoch, GA, sex, race/ethnicity and small for GA (birthweight <10th centile) [29]. Sensitivity analysis was done to adjust for possible overestimation by electronic capture.

In the NICU subgroup the aRR could not be assessed because data were unavailable in neonates admitted from the DR to the newborn nursery. Thus, the association of pneumothorax with DR-CPAP was assessed by logistic regression analysis to yield adjusted odds ratio (aOR), which was also adjusted for $\mathrm{DR}-\mathrm{O}_{2}$, one-minute Apgar score and respiratory distress. 
Table 1. Demographics.

\begin{tabular}{|c|c|c|c|}
\hline Variable & Epoch-1 01/2012-03/2017 & Epoch-2 04/2017-12/2020 & $P$ value \\
\hline Full cohort & $n=51,818$ & $n=42,651$ & \\
\hline Gestational age, mean \pm SD, weeks & $39.0 \pm 1.4$ & $38.9 \pm 1.4$ & $<0.001$ \\
\hline Birth weight, mean $\pm S D, g$ & $3362 \pm 493(n=51,802)$ & $3346 \pm 489(n=42,639)$ & $<0.001$ \\
\hline Birth length, mean $\pm S D, c m$ & $49.4 \pm 2.9(n=51,747)$ & $50.4 \pm 2.7(n=42,583)$ & $<0.001$ \\
\hline Intrauterine growth restriction, $n /$ total (\%) & $1690 / 51,733(3.3)$ & $2563 / 42,571(6.0)$ & $<0.001$ \\
\hline Small for gestational age, $n(\%)$ & $104 / 51,802(0.2)$ & $106 / 42,639(0.2)$ & 0.12 \\
\hline Race and ethnicity, $n$ (\%) & & & $<0.001$ \\
\hline Hispanic & $41,437(80.0)^{a}$ & $32,519(76.2)^{b}$ & \\
\hline Black, non-Hispanic & $6414(12.4)^{a}$ & $6792(15.9)^{b}$ & \\
\hline White, non-Hispanic & $2266(4.4)^{\mathrm{a}}$ & $2016(4.7)^{b}$ & \\
\hline Asian & $1271(2.5)^{\mathrm{a}}$ & $945(2.2)^{b}$ & \\
\hline Birth length, mean $\pm S D, c m$ & $49.3 \pm 3.1(n=3966)$ & $49.7 \pm 2.9(n=4093)$ & $<0.001$ \\
\hline Intrauterine growth restriction $n /$ total (\%) & $447 / 3966(11.3)$ & $469 / 4091(11.5)$ & 0.79 \\
\hline Small for gestational age, $n(\%)$ & $499(12.5)$ & $488(11.9)$ & 0.40 \\
\hline Maternal diabetes mellitus, $n(\%)$ & $1012 / 3983(25.4)$ & $1070 / 4100(26.1)$ & 0.48 \\
\hline Female, $n(\%)$ & $1795(45.0)$ & $1914(46.7)$ & 0.13 \\
\hline Race and ethnicity, $n$ (\%) & & & $<0.001$ \\
\hline Hispanic & $2951(74.2)^{\mathrm{a}}$ & $2852(69.6)^{b}$ & \\
\hline Black, non-Hispanic & $649(16.3)^{a}$ & $839(20.5)^{\mathrm{b}}$ & \\
\hline White, non-Hispanic & $273(6.9)$ & $308(7.5)$ & \\
\hline Asian & $103(2.6)$ & $99(2.4)$ & \\
\hline
\end{tabular}

Student $t$-test or chi-square analysis; different alphanumeric superscripts indicate significant pair-wise differences between the two epochs using Bonferroni correction.

SD Standard deviation, NICU Neonatal intensive care unit, IQR Interquartile range.

\section{Sample size}

For the NICU subgroup a total sample size of 319 was estimated to detect an aOR of 2 for the association of pneumothorax with DR-CPAP, with $90 \%$ power and a two-tailed alpha of 0.05 , assuming $14 \%$ DR-CPAP and $5.6 \%$ pneumothorax as previously [11]. For the full cohort, a sample size of 33,752 or 74,391 was estimated assuming (1) that either 1 of 2 or 1 of 10 of neonates, respectively, receiving DR-CPAP would be admitted to the NICU and (2) $0.4 \%$ pneumothorax [11].

A sample size of 2118 was estimated to detect a $50 \%$ decrease in pneumothorax in the NICU subgroup, and a sample size of 1366 or 7186 was needed to detect a 50\% decrease in CPAP-related pneumothorax in the full cohort, assuming $17 \%$ pneumothorax and, respectively, 1:2 or 1:10 NICU admissions after DR-CPAP.

\section{RESULTS}

Full cohort (Supplementary Fig. 3)

The full cohort included 94,469 neonates with an average GA of 39 weeks (Table 1). The proportion of babies of Hispanic ethnicity decreased and those of other racial/ethnic groups and IUGR increased in Epoch-2. Comparison of electronic capture and chart review of pneumothorax yielded a Cohen kappa $>0.9$ (Supplementary Table 2). There was $\geq 90 \%$ agreement for all variables (Supplementary Table 2). Usage of DR-CPAP and occurrence of CPAP-related pneumothorax progressively increased during
Epoch-1 and decreased during Epoch-2 (both $P<0.001)$ (Supplementary Fig. 3). In contrast, the occurrence of pneumothorax without DR-CPAP did not change significantly.

The aRR of pneumothorax after DR-CPAP exposure was $66.44, \mathrm{Cl}$ 53.06-83.20 (Table 2a). The esimated aRD was $0.10, \mathrm{Cl} 0.09-0.12$ and the aNNH 10, $\mathrm{Cl} 8-11$. Sensitivity analysis correcting for false positive pneumothorax (Supplementary Table 2) yielded a RD of 0.08 (Cl 0.07-0.09) and NNH of $13(\mathrm{Cl} 11-15)$.

The percent of NICU admissions with respiratory distress, including transient tachypnea, decreased in Epoch-2 $(P<0.001)$; median length of NICU stay also decreased $(P<0.001)$ (Table 3$)$. The percent NICU admissions after DR-CPAP decreased from Epoch-1 to Epoch-2 $(P<0.001)$ (Table 3).

\section{NICU subgroup}

In the entire NICU subgroup, the aOR of pneumothorax with DRCPAP among neonates without $\mathrm{DR}^{-\mathrm{O}_{2}}$ exposure, $31.46 \mathrm{(Cl}$ 19.68-50.28), was almost four times that among neonates with DR- $\mathrm{O}_{2}$ exposure, $8.33(\mathrm{Cl} 5.39-12.88)(P<0.001)$ (Table 2b). The aOR of pneumothorax with Epoch reached significance $(P<0.001)$ if CPAP was removed from the model (Fig. 1).

DR-CPAP was started at $5 \mathrm{~cm} \mathrm{H}_{2} \mathrm{O}$ in $99.7 \%$ and rarely increased to $6 \mathrm{~cm}(n=29)$ or $7 \mathrm{~cm}(n=1)$. Among 1005 neonates with DRCPAP, $252(25 \%)$ were taken off CPAP in the DR; the aOR of 
Table 2. Association of baseline variables with pneumothorax on 1st day, 1st chest X-ray among neonates in the two cohorts (excluding DRPPV). a. Full cohort. b. NICU subgroup, excluding PPV or CPAP initiated in the neonatal intensive care unit. c. Association of variables with pneumothorax on 1st day, 1st chest X-ray among neonates who were exposed to DR-CPAP in the NICU subgroup (excluding DR-PPV).

\begin{tabular}{|c|c|c|}
\hline Factor & $\begin{array}{l}\text { Adjusted relative } \\
\text { risk }(95 \% \mathrm{Cl})\end{array}$ & $P$ Value \\
\hline \multicolumn{3}{|l|}{ a. Full cohort* } \\
\hline Epoch-2 vs Epoch-1 & $0.711(0.568-0.890)$ & 0.003 \\
\hline DR-CPAP vs no DR-CPAP & $66.441(53.057-83.201)$ & $<0.001$ \\
\hline Gestational age (per week) & $1.317(1.233-1.406)$ & $<0.001$ \\
\hline Male vs. female & $1.664(1.329-2.082$ & $<0.001$ \\
\hline Race/ethnicity & & $<0.001$ \\
\hline Hispanic & Ref & \\
\hline Black, non-Hispanic & $0.411(0.273-0.618)$ & $<0.001$ \\
\hline White, non-Hispanic & $1.021(0.666-1.565)$ & 0.93 \\
\hline Asian & $0.372(0.119-1.170)$ & 0.09 \\
\hline Other or unknown & $0.960(0.368-2.500)$ & 0.93 \\
\hline Small for gestational age & $2.058(0.947-4.473)$ & 0.07 \\
\hline Factor & Adjusted odds ratio $(\mathrm{Cl})$ & $P$ Value \\
\hline
\end{tabular}

b. NICU subgroup, excluding PPV or CPAP initiated in the neonatal intensive care unit**

\begin{tabular}{|c|c|c|}
\hline Epoch-2 vs Epoch-1 & $0.78(0.58-1.05)$ & 0.10 \\
\hline DR-CPAP vs no DR-CPAP & & $<0.001$ \\
\hline With $\mathrm{DR}-\mathrm{O}_{2}$ & $8.33(5.39-12.88)$ & $<0.001$ \\
\hline Without DR-O ${ }_{2}$ & $31.46(19.68-50.28)$ & $<0.001$ \\
\hline Gestational age (per week) & $1.47(1.35-1.60)$ & $<0.001$ \\
\hline Male vs. female & $1.67(1.26-2.22)$ & $<0.001$ \\
\hline Race/ethnicity: & & $<0.001$ \\
\hline Hispanic & Ref & \\
\hline Black, not Hispanic & $0.36(0.22-0.56)$ & $<0.001$ \\
\hline White, not Hispanic & $0.83(0.50-1.39)$ & 0.48 \\
\hline Other or unknown & $0.54(0.21-1.37)$ & 0.19 \\
\hline Small for gestational age & $0.90(0.57-1.42)$ & 0.65 \\
\hline Maternal diabetes mellitus & $0.38(0.24-0.61)$ & $<0.001$ \\
\hline Apgar score at $1 \mathrm{~min}$ & $1.23(1.09,1.39)$ & 0.001 \\
\hline Respiratory distress on first day & Ref & \\
\hline None & a & 0.996 \\
\hline $\begin{array}{l}\text { Respiratory distress } \\
\text { syndrome }\end{array}$ & $0.12(0.08-0.18)$ & $<0.001$ \\
\hline $\begin{array}{l}\text { Transient tachypnea or } \\
\text { retained lung fluid }\end{array}$ & $0.25(0.16-0.41)$ & $<0.001$ \\
\hline Pneumonia & $0.20(0.06-0.71)$ & 0.01 \\
\hline $\begin{array}{l}\text { Meconium aspiration } \\
\text { syndrome }\end{array}$ & $0.19(0.08-0.47)$ & $<0.001$ \\
\hline \multicolumn{3}{|l|}{ Other } \\
\hline actor & $\begin{array}{l}\text { Adjusted odds ratio } \\
\text { (95\% Cl) }\end{array}$ & $P$ Value \\
\hline
\end{tabular}

c. Association of variables with pneumothorax on 1st day, 1st chest X-ray among neonates who were exposed to DR-CPAP in the NICU subgroup (excluding DR-PPV)***

\begin{tabular}{lll} 
Gestational age (per week) & $1.58(1.39-1.80)$ & $<0.001$ \\
$\begin{array}{ll}\text { Race/ethnicity } \\
\text { Hispanic }\end{array}$ & Ref & 0.009 \\
\hline Black, non-Hispanic & $0.32(0.16-0.65)$ & 0.002 \\
\hline White, non-Hispanic & $1.36(0.66-2.82)$ & 0.41 \\
\hline Other or unknown & $0.64(0.18-2.29)$ & 0.49
\end{tabular}

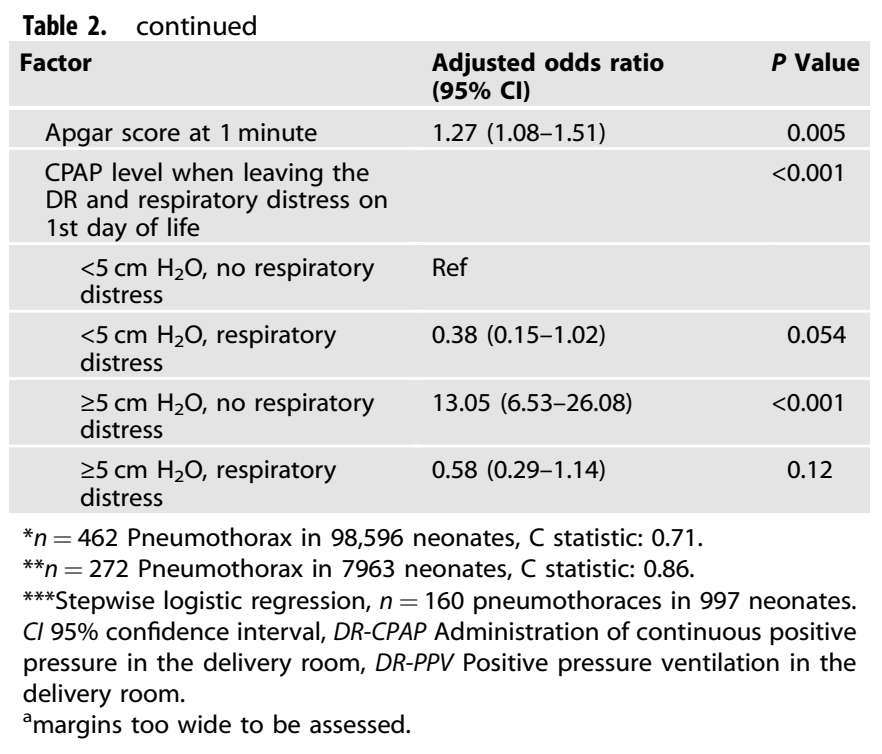

pneumothorax was higher among those without respiratory distress who left the DR with CPAP level $\geq 5 \mathrm{~cm}$ (Table $2 \mathrm{c}$ ).

Among neonates not receiving DR-PPV/O $\mathrm{O}_{2}$, DR-CPAP usage decreased significantly from $6.9 \%$ in Epoch-1 to $1.2 \%$ in Epoch-2 $(P<0.001)$ (Table 3, Fig. 2A). This decrease of CPAP usage was reflected in a change in the primary outcome of DR-CPAPassociated pneumothorax from $1.4 \%$ to $0.06 \%(P<0.001)$ and a decrease in any pneumothorax from 3.0 to $1.2(P<0.001)$ but not in spontaneous pneumothorax $(P=0.22)$ (Fig. 2B-D). The frequency of CPAP-associated pneumothorax among those exposed to DR-CPAP decreased from $20.2 \%$ to $5.3 \%$ from Epoch-1 to Epoch-2 $(P=0.04)$ (Table 3$)$. There was no change in thoracentesis or thoracostomy or in time of admission for meconium aspiration syndrome. The percentage of transient tachypnea or retained lung fluid and the percentage of pneumonia decreased in Epoch-2 $(P<0.05)$.

Among neonates exposed to DR-O ${ }_{2}$, DR-CPAP usage decreased from $54 \%$ in Epoch-1 to $27 \%$ in Epoch-2 $(P<0.001)$ (Table 3$)$. Occurrence of any pneumothorax on the first day of life decreased from $9.4 \%$ to $6.2 \%(P<0.001)$ and occurrence of CPAP-associated pneumothorax decreased from $7.8 \%$ to $3.8 \%(P<0.001)$. Occurrence of spontaneous pneumothorax increased from $1.3 \%$ to $2.3 \%$ $(P=0.049)$. Among neonates with spontaneous pneumothorax, none of the variables found to be independently associated with pneumothorax in the entire NICU cohort (Table 2b) changed in Epoch-2 (data not shown). Among all neonates exposed to $\mathrm{DR}-\mathrm{O}_{2}$ the percentage of pneumonia and that of other respiratory distress decreased in Epoch-2 $(P<0.05)$.

\section{DISCUSSION}

This is to best of our knowledge the first study showing that deimplementing DR-CPAP at 5-7 $\mathrm{cm} \mathrm{H}_{2} \mathrm{O}$ in neonates delivered at 35-43 weeks' GA with labored breathing but not receiving DR$\mathrm{PPV} / \mathrm{O}_{2}$ was followed by a decrease in DR-CPAP-associated pneumothorax and DR-related pneumothorax without worsening of other outcomes. There was also a decrease in DR-CPAP and in DR-CPAP-associated pneumothorax in neonates receiving DR- $\mathrm{O}_{2}$ in Epoch-2. The aOR of pneumothorax with DR-CPAP was higher in neonates who did not receive $D R-O_{2}$ than those who did, as reported previously [11]. In the full cohort DR-CPAP was associated with an increased risk of pneumothorax on the first day of life in neonates not receiving DR-PPV. The high aRR of 66 
Table 3. Outcome Variables During the two Epochs.

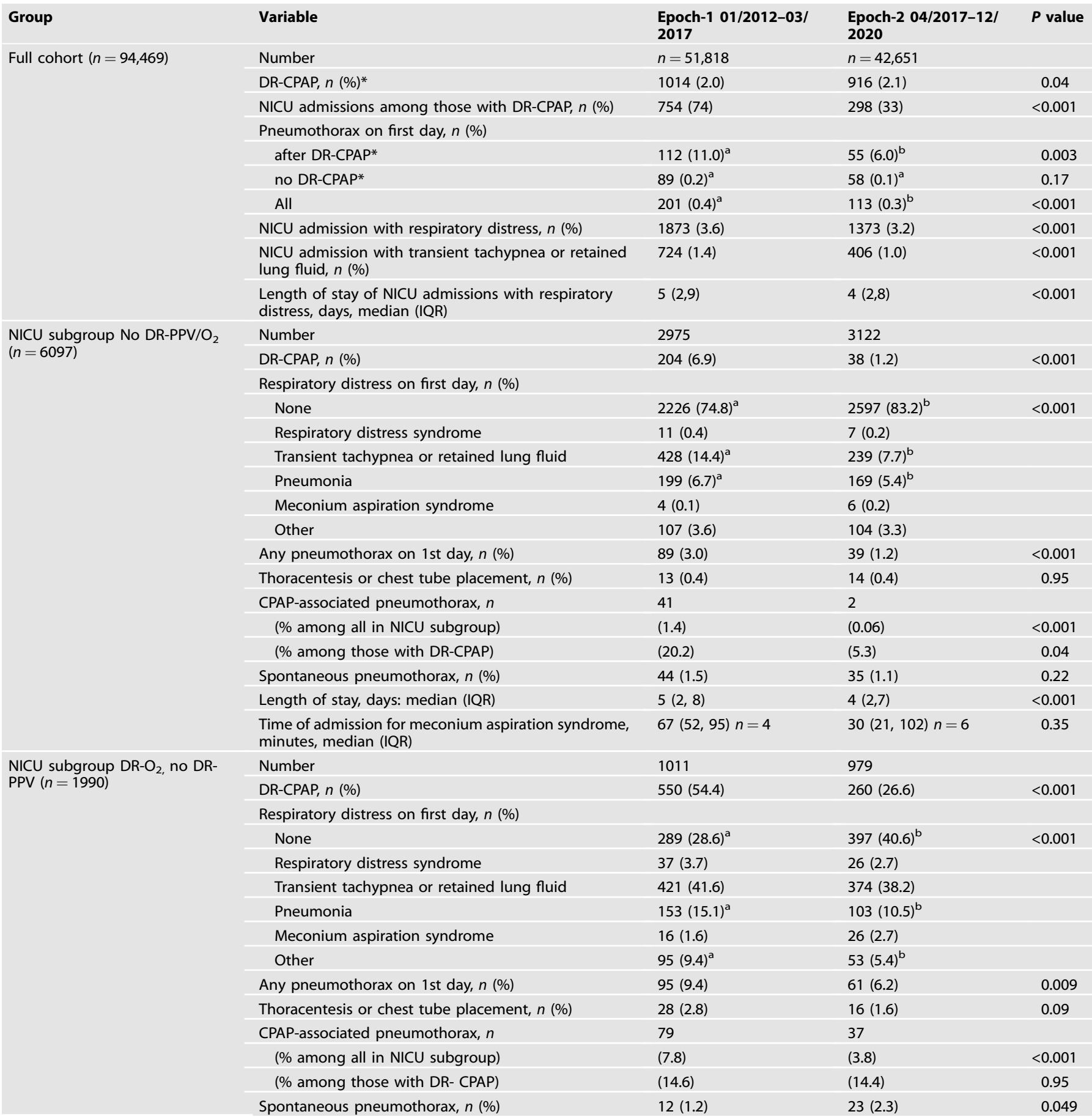

Data are number (\%) or median (interquartile range).

Fisher's exact test, chi-square analysis or Mann-Whitney test.

Pneumothorax on first chest radiogram on first day of life.

CPAP-associated pneumothorax, confirmed pneumothorax on 1st radiogram and during the $1 \mathrm{st} 24 \mathrm{~h}$ after DR-CPAP, excluding positive pressure initiated in the NICU and prior PPV; spontaneous pneumothorax, confirmed pneumothorax on 1st radiogram and 1st day postnatal without any prior PPV or CPAP. *predicted per NLP algorithm.

Different alphanumeric superscripts indicate significant pair-wise differences between the two epochs using Bonferroni correction.

NICU Neonatal intensive care unit, DR Delivery room, IQR Interquartile range, DR-CPAP Delivery room continuous positive airway pressure.

and low frequency of pneumothorax led to a aRD of 0.10 and aNNH of 10.

CPAP decreases morbidity and mortality in preterm infants with respiratory distress syndrome (RDS) [1, 2]. CPAP facilitates airway fluid clearance, improves lung compliance and oxygenation and decreases apnea [3]. Systematic review of RCTs using DR-CPAP instead of endotracheal intubation in extreme preterm infants at risk for RDS showed an increase in frequency of pneumothorax in 


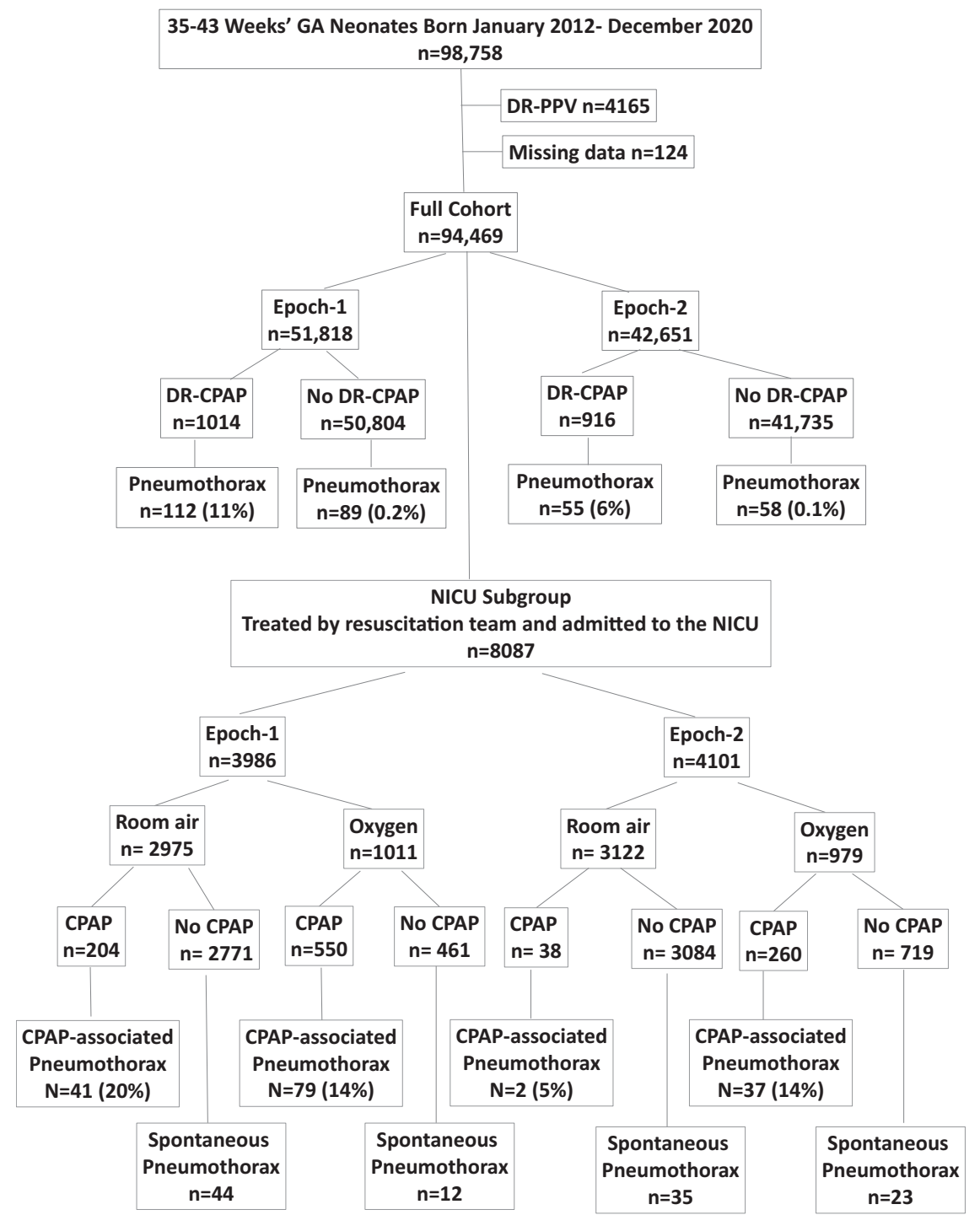

Fig. 1 Flow diagram: pneumothorax on first day of life vs. DR-CPAP and DR-O $\mathbf{O}_{2}$ CPAP-associated pneumothorax, confirmed pneumothorax on 1st chest radiogram \& 1st day of life after exposure to DR-CPAP without DR-PPV, excluding positive pressure initiated in the NICU and prior PPV; spontaneous pneumothorax, confirmed pneumothorax on 1st chest radiogram \& 1st day of life without prior exposure to PPV or CPAP. Abbreviations: GA gestational age, DR delivery room, NICU neonatal intensive care unit, DR-PPV delivery room positive pressure ventilation, CPAP continuous positive airway pressure, PTX pneumothorax on 1st chest radiogram \& 1st day of life.

one trial using DR-CPAP at $8 \mathrm{~cm} \mathrm{H} \mathrm{H}_{2} \mathrm{O}$, but not other trials using 5 $\mathrm{cm}[4,5]$. Higher risk of CPAP-associated pneumothorax in late preterm and term infants is likely due to higher surfactant load at delivery, lower surface tension, higher lung compliance and lower chest compliance than in preterm infants [10-17].

In this study, the decrease in NICU admissions for respiratory distress in Epoch-2 was mediated by less pneumothorax and less transient tachypnea. Successful perinatal transition without exposure to DR-CPAP among neonates not receiving DR-PPV/O $\mathrm{O}_{2}$ may have resulted from less exposure to dead space due to the internal space of the mask on CPAP [30, 31]. Implementation of the Update of the Japan Resuscitation Council Guidelines in 2010 resulted in increased prevalence of respiratory support within $24 \mathrm{~h}$ of life [30]. Reduction of DR-CPAP use in neonates receiving $\mathrm{DR}-\mathrm{O}_{2}$ (typically among those receiving $<40 \% \mathrm{O}_{2}$ ) in Epoch-2 likely resulted from expansion of clinical practice beyond bounderies of the protocol, as reported in other studies $[32,33]$.

The increase in spontaneous pneumothorax in Epoch-2 among neonates exposed to $\mathrm{DR}-\mathrm{O}_{2}$ was unexpected. Since it occurred without any change in variables shown to be independently associated with pneumothorax, it is possible that the increase in spontaneous pneumothorax in Epoch-2 could be due to other variables that were not available in this study. Alternatively, it is possible that the increase in spontaneous pneumothorax resulted from the fact that some DR-associated pneumothoraces might not have been caused by CPAP.

The higher frequency of pneumothorax in males compared with females observed in the current study was already observed in other studies in neonates including our previous study $[11,15]$. Spontaneous pneumothorax is more frequent in males than females in children and adults [34]. We are not aware of mechanisms involved.

Strengths of this study include (1) availability of information on DR-PPV, DR-CPAP, pneumothorax on the first day and respiratory outcomes, NICU admission and length of stay in a large prospective full cohort, yielding values of aRR, aRD and aNNH; (2) electronic data capture using validated algorithms with almost near-perfect agreement (kappa $\geq 0.81$ ) [26] and $\geq 90 \%$ observed agreement for all variables; (3) strict definition of CPAP-associated pneumothorax in a nested NICU subgroup; (4) change in practice 
$\mathbf{A}$

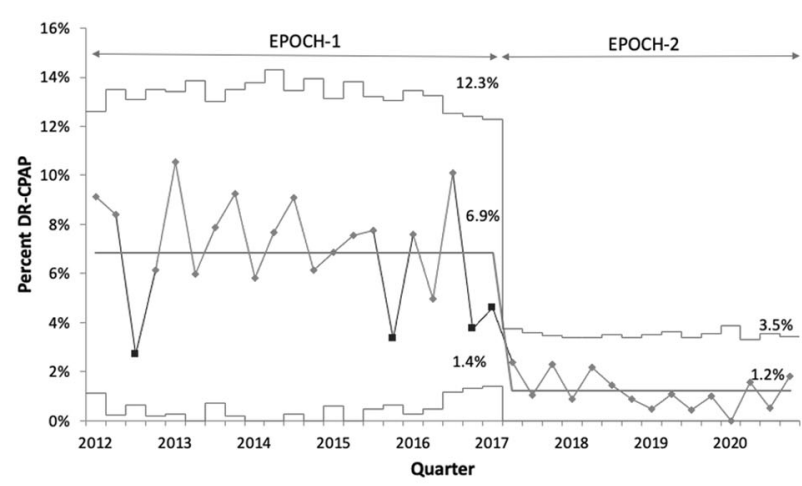

B

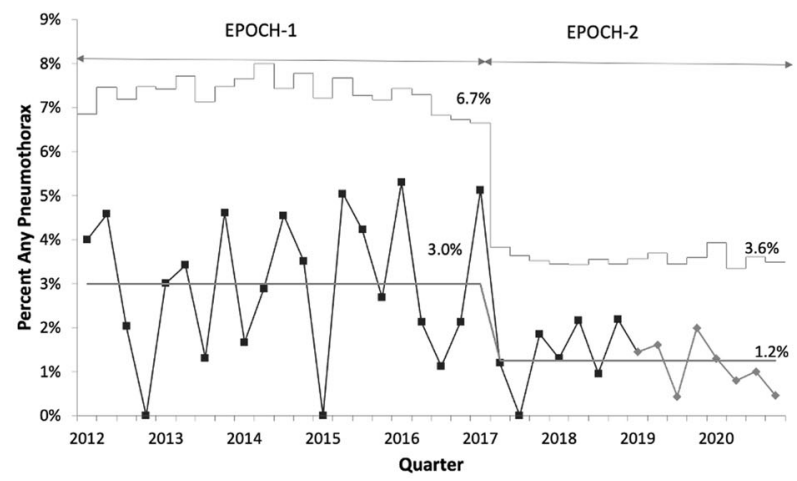

C

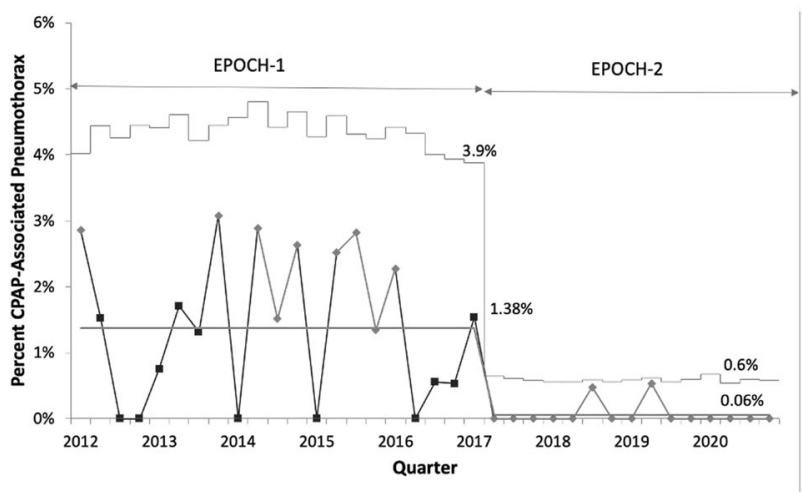

D

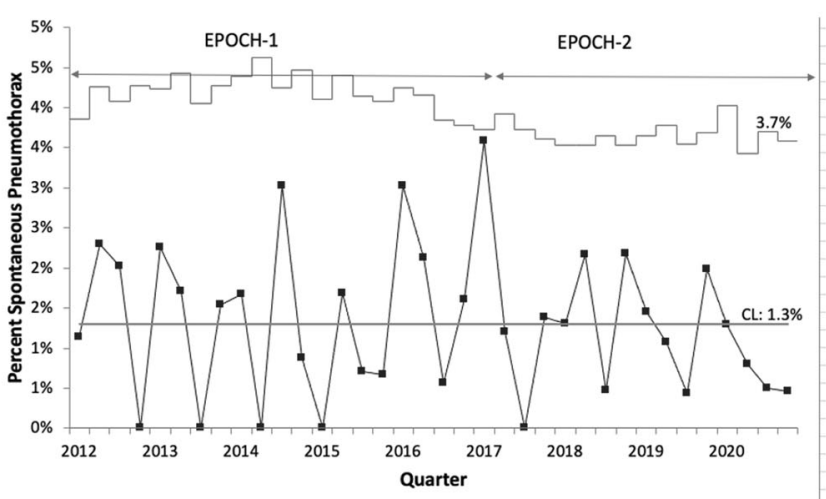

Fig. 2 Changes over time (Control P charts) in exposure to DR-CPAP (Panel A) and pneumothorax during the first day of life (Panels B-D) among 6097 neonates in NICU subgroup who did not receive $\mathrm{O}_{2}$ in the delivery room during the two Epochs. Panel (A): DR-CPAP: The frequency of DR-CPAP decreased from 6.9\% in Epoch-1 to 1.2\% in Epoch-2. Panel (B). Any pneumothorax: The frequency of any pneumothorax decreased from $3.0 \%$ in Epoch-1 to $1.2 \%$ in Epoch-2. Panel (C). CPAP-associated pneumothorax: The frequency of CPAP-associated pneumothorax decreased from 1.38\% in Epoch-1 to 0.06\% in Epoch-2. Panel (D) Spontaneous pneumothorax: The frequency of spontaneous pneumothorax did not change significantly from Epoch-1 to Epoch-2. CPAP-associated pneumothorax, confirmed CPAP-associated pneumothorax (following DR-CPAP, pneumothorax visible on 1st radiogram and 1st day postnatal, excluding positive pressure initiated in the NICU and prior PPV); spontaneous pneumothorax, confirmed pneumothorax on 1st radiogram and 1st day postnatal without any prior PPV or CPAP. Abbreviations: DR-CPAP delivery room continuous positive airway pressure, NICU neonatal intensive care unit, $\mathrm{O}_{2}$ oxygen, Epoch-1 baseline, Epoch-2 after de-implementation of DR-CPAP in neonates not needing oxygen or positive pressure ventilation in the delivery room, UCL upper control limit, CL central line, CPAP continuous positive airway pressure, DR delivery room, PPV positive pressure ventilation.

involving de-implementation of DR-CPAP in neonates not needing DR-PPV/O 2 with strict guidelines about indication for radiograms and high compliance with processes of care; (5) consistency of results by using standard statistics vs analysis of change with time. These factors eliminated several limitations in a previous manuscript $[11,12,18]$.

Limitations of this study included (1) lack of randomization, (2) lack of availability of point of care ultrasonogram to diagnose pneumothorax leading to inability to assess the frequency of asymptomatic pneumothorax and to determine whether an symptomatic pneumothorax was present before CPAP or PPV, (3) lack of individual chart review in the full cohort, leading to only estimates of RR, RD and $\mathrm{NNH}$ (4) lack of exact data on the timing and duration of administration of each level of DR-CPAP and inability to differentiate the roles of face mask vs nasal prongs CPAP on pneumothorax development, (5) lack of standardization of the use of CPAP, which may have resulted in overuse of CPAP in some cases; (6) lack of data on CPAP $<5 \mathrm{~cm} \mathrm{H}_{2} \mathrm{O}$ and (7) lack of data on severity of respiratory distress. This study was not designed to assess benefits and risks of DR-CPAP at $5-7 \mathrm{~cm} \mathrm{H}_{2} \mathrm{O}$ in neonates delivered at 35-43 weeks' GA with labored breathing and persistent cyanosis, in whom RCTs and observational studies have shown that DR-CPAP may improve respiratory distress [20-25, 35].

De-implementing DR-CPAP $\geq 5 \mathrm{~cm}$ in neonates $\geq 35$-week $\mathrm{GA}$ with labored breathing but not receiving $\mathrm{DR}-\mathrm{PPV} / \mathrm{O}_{2}$ was followed by a decrease in DR-CPAP-associated pneumothorax without worsening of other outcomes. Studies including RCTs are needed to test whether using DR-CPAP at $<5 \mathrm{~cm}$ may improve outcomes in neonates $\geq 35$-week GA with mild respiratory distress without increasing the risk of pneumothorax.

\section{REFERENCES}

1. Gregory GA, Kitterman JA, Phibbs RH, Tooley WH, Hamilton WK. Treatment of the idiopathic respiratory-distress syndrome with continuous positive airway pressure. N. Engl J Med. 1971;284:1333-40.

2. Avery ME, Tooley WH, Keller JB, Hurd SS, Bryan MH, Cotton RB, et al. Is chronic lung disease in low birth weight infants preventable? A survey of eight centers. Pediatrics 1987;79:26-30.

3. Hamalek LP, Morley C. Continuous positive airway pressure during neonatal resuscitation. Clin Perinatol. 2006;33:83-98.

4. Subramaniam P, Ho JJ, Davis PG. Prophylactic nasal continuous positive airway pressure for preventing morbidity and mortality in very preterm infants. Cochrane Database Syst Rev. 2016;6:CD001243.

5. Morley CJ, Davis PG, Doyle LW, Brion LP, Hascoet JM, Carlin JB. COIN Trial Investigators. Nasal CPAP or intubation at birth for very preterm infants. N. Engl J Med. 2008;358:700-8.

6. Perlman JM, Wyllie J, Kattwinkel J, Atkins DL, Chameides L, Goldsmith JP, et al Neonatal resuscitation: 2010 international consensus on cardiopulmonary resuscitation and emergency cardiovascular care science with treatment recommendations. Pediatrics 2010;126:e1319-e1344. 
7. Kattwinkel J, Perlman JM, Aziz K, Colby C, Fairchild K, Gallagher J, et al. Neonatal Resuscitation: 2010 American Heart Association Guidelines for Cardiopulmonary Resuscitation and Emergency Cardiovascular Care. Pediatrics 2010;126:e1400-e1413.

8. Tamura M, Wada M, Ishikawa G, Kusakawa I, Goishi K, Sugiura T, et al. JRC Guidelines 2010 English version: NCPR; Neonatal Cardiopulmonary Resuscitation. Secondary JRC Guidelines 2010. https://www.japanresuscitationcouncil.org/wpcontent/uploads/2016/02/20121011_NCPR. Accessed 04/06/2021.

9. Richmond S, Wyllie J. European Resuscitation Council Guidelines for Resuscitation 2010 Section 7. Resuscitation of babies at birth. Resuscitation. 2010;81:1389-99.

10. Hishikawa K, Goishi K, Fujiwara T, Kaneshige M, Ito Y, Sago H. Pulmonary air leak associated with CPAP at term birth resuscitation. Arch Dis Child Fetal Neonatal Ed. 2015;100:F382-F387.

11. Smithhart W, Wyckoff MH, Kapadia V, Jaleel M, Kakkilaya V, Brown LS, et al. Delivery room continuous positive airway pressure and pneumothorax. Pediatrics 2019;144:e20190756.

12. Jaleel MA, Smithhart W, Brion LP. Re: delivery room continuous positive airway pressure and pneumothorax. https://pediatrics.aappublications.org/content/144/ 3/e20190756/tab-e-letters\#re-delivery-room-continuous-positive-airwaypressure-and-pneumothorax, Accessed 10/25/2019.

13. Clevenger $L$, Britton JR. Delivery room continuous positive airway pressure and early pneumothorax in term newborn infants. J Neonatal Perinat Med. 2017;10:157-61.

14. Claessen CC, Strand ML. Understanding the risks and benefits of delivery room CPAP for term infants. Pediatrics 2019;144:e20191720.

15. Duong HH, Mirea L, Shah PS, Yang J, Lee SK, Sankaran K. Pneumothorax in neonates: trends, predictors and outcomes. J Neonatal Perinat Med. 2014;7:29-38.

16. Gerhardt T, Bancalari E. Chestwall compliance in full-term and premature infants. Acta Paediatr Scand. 1980;69:359-64.

17. Poets CF, Rüdiger M. Mask CPAP during neonatal transition: too much of a good thing for some term infants? Arch Dis Child Fetal Neonatal Ed. 2015;100:F378-9.

18. Spillane NT, Chivily C, Andrews T. Short term outcomes in term and late preterm neonates admitted to the well-baby nursery after resuscitation in the delivery room. J Perinatol. 2019;39:983-9.

19. Fatemizadah R, Lohmann P, Fernandez CJ. Delivery Room CPAP in Late-Preterm and Term Infants: Jury's Still Out. Comment, https://pediatrics.aappublications. org/content/144/3/e20190756/tab-e-letters\#delivery-room-cpap-in-late-pretermand-term-infants-jury\%E2\%80\%99s-still-out, Accessed 09/23/2019.

20. Osman AM, El-Farrash RA, Mohammed EH. Early rescue Neopuff for infants with transient tachypnea of newborn: a randomized controlled trial. J Matern Fetal Neonatal Med. 2019;32:597-603.

21. Moresco L, Romantsik O, Calevo MG, Bruschettini M. Non-invasive respiratory support for the management of transient tachypnea of the newborn. Cochrane Database Syst Rev. 2020;4:CD013231.

22. Pandita A, Murki S, Oleti TP, Tandur B, Kiran S, Narkhede S, et al. Effect of nasal continuous positive airway pressure on infants with meconium aspiration syndrome: a randomized clinical trial. JAMA Pediatr. 2018;172:161-5.

23. Buckmaster AG, Arnolda G, Wright IM, Foster JP, Henderson-Smart DJ. Continuous positive airway pressure therapy for infants with respiratory distress in non tertiary care centers: a randomized, controlled trial [published correction appears in Pediatrics. Pediatrics. 2007;120:509-18.

24. Manley BJ, Arnolda GRB, Wright IMR, Owen LS, Foster JP, Huang L, et al. HUNTER trial investigators. nasal high-flow therapy for newborn infants in special care nurseries. N Engl J Med. 2019;380:2031-40.

25. Celebi MY, Alan S, Kahvecioglu D, Cakir U, Yildiz D, Erdeve O, et al. Impact of prophylactic continuous positive airway pressure on transient tachypnea of the newborn and neonatal intensive care admission in newborns delivered by elective cesarean section. Am J Perinatol. 2016;33:99-106.

26. Kimia AA, Savova G, Landschaft A, Harper MB. An introduction to natural language processing: how you can get more from those electronic notes you are generating. Pediatr Emerg Care. 2015;31:536-41.

27. Scheid LM, Brown LS, Clark C, Rosenfeld CR. Data electronically extracted from the electronic health record require validation. J Perinatol. 2019;39:468-74.

28. Penfold RB, Zhang F. Use of interrupted time series analysis in evaluating health care quality improvements. Acad Pediatr. 2013;13:S38-44.

29. Olsen IE, Groveman SA, Lawson ML, Clark RH, Zemel BS. New intrauterine growth curves based on United States data. Pediatrics 2010;125:e214-224.

30. Hishikawa $\mathrm{K}$, Fujinaga $\mathrm{H}$, Ito $\mathrm{Y}$. Increased dead space in face mask continuous positive airway pressure in neonates. Pediatr Pulmonol. 2017;52:107-11.
31. Hishikawa K, Fujinaga H, Fujiwara T, Goishi K, Kaneshige M, Sago $H$, et al. Respiratory stabilization after delivery in term infants after the update of the Japan resuscitation council guidelines in 2010. Neonatology 2016;110:1-7.

32. LeVan JM, Wyckoff MH, Ahn C, Heyne R, Sánchez PJ, Chalak L, et al. Change in care among nonenrolled patients during and after a randomized trial. Pediatrics 2013;132:e960-970.

33. LeVan JM, Brion LP, Wrage LA, Gantz MG, Wyckoff MH, Sánchez PJ, et al. Eunice Kennedy shriver NICHD neonatal research network. change in practice after the surfactant, positive pressure and oxygenation randomised trial. Arch Dis Child Fetal Neonatal Ed. 2014;99:F386-90.

34. Goldman RD. Spontaneous pneumothorax in children. Can Fam Physician. 2020; 66:737-8.

35. Chiruvolu A, Claunch KM, Garcia AJ, Petrey B, Hammonds K, Mallett LH. Effect of continuous positive airway pressure versus nasal cannula on late preterm and term infants with transient tachypnea of the newborn. J Perinatol. 2021;41:1675-80.

\section{AUTHOR CONTRIBUTIONS}

Dr. Stocks drafted the initial manuscript and collected data. Drs Smithhart, Wyckoff, Jaleel, Kapadia, Kakkilaya and Nelson conceptualized and designed the study. Dr. Brenan planned methods of analysis. Dr. Mangona reviewed the chest radiograms of neonates with questionable pneumothorax; she was blinded to delivery room therapy. Ms. Burchfield and Ms. Thomas collected dated. Brion conceptualized and designed the project, collected, and analyzed the data. Mr. Clark worked at optimizing algorithms to extract data on pneumothorax (with Dr. Stocks) as well as DR-CPAP, DR-PPV and DR-O2 (with Dr. Brenan) from the electronic medical record system and extracted data for the full cohort. Mr. Brown analyzed the data using statistical tools. All authors participated in the interpretation of the data, critically reviewed the revisions, approved the final manuscript as submitted and agree to be accountable for all aspects of the work. Preliminary results were published as a comment in Pediatrics ${ }^{17}$ and as an abstract to the Annual Meeting of the Pediatric Academy Societies: Stocks E, Jaleel M, Smitthart W, Burchfield P, Thomas A, Mangona, KLM, Kapadia V, Wyckoff MH, Kakkilaya V, Weaver J, Brion LP. Reduction in Delivery Room (DR) Continuous Positive Airway Pressure (CPAP)-Associated Pneumothorax in Term and Late-Preterm Neonates. Accepted for oral presentation at PAS, Philadelphia, PA, 5/2/2020; cancelled for COVID-19/SARS-Cov-2; presented online at Virtual Regional Neonatal Research Conference 6/16/2020. The datasets generated and/or analyzed during the current study are available from the corresponding author on reasonable request.

\section{COMPETING INTERESTS}

The authors declare no competing interests.

\section{ETHICS APPROVAL AND CONSENT TO PARTICIPATE}

This project was initially approved as quality improvement by the University of Texas Southwestern Medical Center Institutional Review Board and by Parkland Health and Hospital Systems. The entire project including the retrospective full cohort as described was later approved as a research project. The need for informed consent was waived for the entire project.

\section{ADDITIONAL INFORMATION}

Supplementary information The online version contains supplementary material available at https://doi.org/10.1038/s41372-022-01334-4

Correspondence and requests for materials should be addressed to Luc P. Brion.

Reprints and permission information is available at http://www.nature.com/ reprints

Publisher's note Springer Nature remains neutral with regard to jurisdictional claims in published maps and institutional affiliations. 